part of the adult structures. In contrast, the vertebrate egg is considered highly regulative since the whole organism may be reconstituted from any single descendent cell, at least through the first several divisions of the egg. That the distinction between mosaic and regulative development has been overdrawn was argued by K. Sander (AlbertLudwig's-Universität, Freiburg). $\mathrm{He}$ presented experiments which demonstrated convincingly that in insects the early developmental stages are to a degree still regulative. In the leaf hopper, if material from the posterior pole of the egg is moved anteriorly the fate of cells forming in adjacent regions of the blastoderm can be altered. When the eggs of blowflies are pinched by ligation the fate of cells adjacent to the ligated region is altered. If the egg is closed off in the middle, the anterior portion will generate only the anterior segments 1, 2, 3 and 4 while the posterior portion forms only segments $7,8,9$ and 10 . The central segments do not form. However, asymmetrical ligations can generate those segments (for example, 1, 2, 3 and 6, 7, 8, 9 and 10). These results are most readily interpreted by assuming that an inducer gradient exists within the egg which is re-established after ligation and that the fate of cells in the central region is determined by the re-established gradients. Sander argued that this prepattern formation which gives rise to the determined blastoderm occurs late in the primitive insects and with evolution is projected back into the oocyte giving rise to the so-called mosaic developmental pattern where each cell that arises in the young embryo seems to have a defined fate.

\section{Pattern formation}

P. Sengal (University of Grenoble, France) summarised his elegant studies on pattern formation in the skin of amniotes. This was one of the few presentations at the meeting dealing with vertebrate development. Whereas the epidermis is the sole participant in forming such major surface features as hair, feathers and scales, the dermis plays a crucial role in determining the topographical pattern of these elements. Sengal was able to demonstrate the role these two tissues play in differentiation by culturing together epidermis and dermis from different sources (mouse, chick, duck and lizard) on chick allantoic membrane. In a.ll cases the epidermis initiated development of structures appropriate to its ancestry independent of the origin of the underlying dermis but the pattern of epidermally-derived elements within the epidermis seemed to be controlled by the dermis. Sengal found that dermis from the mouse upper lip (which nor- mally forms large and small hairs) induced the formation of large and small placoids in lizard epidermis and large and small feather follicles in chick epidermis, whereas mouse dorsal epidermis (which normally forms small hairs only) induced a dense pattern of small scales or feathers in the appropriate epidermis. Various combinations gave essentially the same answerpattern information is transferred from the dermis to the epidermis even between mouse and lizard tissues. But although gross pattern information can apparently be transmitted between tissues derived from animals of different classes, the structures formed by the epidermis in these conditions resemble only the early stages of differentiation of these elements. Apparently further specific instructions concerning the nature of the hair or

\title{
Thermal environment of plants
}

\section{from Peter D. Moore}

THE annual report of the Department of Plant Biology of the Carnegie Institution can usually be relied upon to supply stimulating ideas and information in the field of plant ecophysiology and the recently issued report for 1973-74 is no exception. Of particular interest is a series of field and laboratory experiments relating to the influence of the thermal environment upon the growth and development of several plant species.

The field experiments are reported by Björkman et al. (Carnegie Inst. Yb., 73, 748; 1974) and concern transplantation into two experimental 'gardens', one in Death Valley, a desert site with high temperatures and low rainfall (less than $40 \mathrm{~mm}$ ) and the other at Bodega Head on the coast of California, where conditions are cool and humid (annual rainfall is 750-1,000 $\mathrm{mm}$ ). A total of 17 species were used in transplant experiments, including some species of cool, oceanic climates and some from desert environments; many belong to the family Chenopodiaceae, including species of both $\mathrm{C}_{3}$ and $\mathrm{C}_{4}$ type (see Nature, 252, 438; 1974). In Death Valley all died during the summer if irrigation was withheld. When supplied with water, however, eight of the species tested were capable of survival, but grew better between October and May than they did in full summer (June to September). One species, Tidestromia oblongifolia, not only survived at Death Valley when irrigated, but actually grew better in high summer than in the October to May period. All species excerpt one of the cool, oceanic group failed to survive at Death Valley even when they were irrigated.

A.t the oceanic site, Bodega Head, irrigation had a far less marked effect and all species except one survived. The exception, once again, was $T$. oblongifolia. The experi- ments demonstrate the importance of temperature as a determinant of survival and growth under conditions of ample water supply in these species and they also indicate that adaptations which permit growth at one climatic extreme may preclude survival under less severe conditions.

Transplant experiments have certain disadvantages. Failure to survive at a site may be due to such pressures as predation or parasitism rather than to an adverse physical environment. Björkman and his colleagues have met this objection by conducting controlled environment chamber experiments on four species representative of the various responses observed in the field. The results obtained parallel the field observations. $T$. oblongifolia failed to sustain its growth under a $16^{\circ} \mathrm{C}$ (day) $/ 11{ }^{\circ} \mathrm{C}$ (night) thermal regime whereas it doubled its dry weight in three days when grown at $45^{\circ} \mathrm{C}$ (day)/ $31{ }^{\circ} \mathrm{C}$ (night). These conditions reflect those often experienced at Bodega Head and Death Valley, respectively. The oceanic species again grew better under cooler conditions.

Growth differences between species and between temperature regimes cannot be explained simply in terms of differential translocation of photosynthate because growth analysis experiments showed a similar allocation of material to root, shoot and leaf in all species under both sets of conditions. So temperature must act directly upon metabolic processes, perhaps upon membrane or enzyme stability. The authors also draw attention to the fact that Tidestromia is a $\mathrm{C}_{4}$ plant, as are some of the oceanic types, such as Atriplex sabulosa. The experiments thus confirm the association of the $\mathrm{C}_{4}$ mechanism with adaptation to high temperature environments, but also show that some $\mathrm{C}_{4}$ plants have growth optima at relatively low temperatures. 